\title{
QUALIFICATION ROUTES MESSAGING FOR DYNAMIC SYSTEMS USING A LOGICAL-PROBABILISTIC METHOD
}

\author{
В.В.Глазунов, М.А. Курочкин, С.Г. Попов
}

\section{ОЦЕНКА МАРШРУТОВ ПЕРЕДАЧИ СООБЩЕНИЙ \\ В ДИНАМИЧЕСКИХ СИСТЕМАХ С ИСПОЛЬЗОВАНИЕМ ЛОГИКО-ВЕРОЯТНОСТНОГО МЕТОДА}

In this paper we have considered the problem of message routes evaluation in the dynamic network of mobile subscribers. The network of mobile objects is represented by a graph with the time-varying structure. The search of the optimal route at any given time has polynomial complexity. As a solution, we suggest the logical-probabilistic method to build estimates of the routes. This method allows obtaining an analytical expression of the message delivery probability function for a s-connected graph with the given dimension. In this case, the time of searching for an optimal route can be considered as a constant.

FUNCTION OF MESSAGE DELIVERY PROBABILITY; MOBILE OBJECT; DYNAMIC SYSTEM; ROUTE MESSAGING; LOGICAL-PROBABILISTIC METHOD; MESH-NETWORK.

Рассмотрена задача построения оценки маршрутов передачи сообщений в динамической сети мобильных абонентов. Сеть мобильных объектов представлена графом, структура которого меняется во времени. Поиск оптимального маршрута передачи данных в произвольный момент времени требует полиномиального времени. Для решения этой проблемы предложено строить оценки, используя логико-вероятностный метод, позволяющий получить аналитическое выражение функции вероятности доставки сообщения для s-связанного графа заданной размерности. В этом случае время построения оптимального маршрута можно считать константным.

ФУНКЦИЯ ВЕРОЯТНОСТИ ДОСТАВКИ СООБЩЕНИЙ; МОБИЛЬНЫЙ ОБЪЕКТ; ДИНАМИЧЕСКАЯ СИСТЕМА; МАРШРУТ ПЕРЕДАЧИ СООБЩЕНИЙ; ЛОГИКО-ВЕРОЯТНОСТНЫЙ МЕТОД; МЕSН-СЕТИ.

\section{Introduction}

At the present time, more and more attention is paid to research problems of building a cloud-oriented mesh-network of vehicles. The continuous improvement of data transmission assets, network equipment, internetworking methods and cloud services access methods allow defining new tasks of providing information services to mobile networks subscribers. A special interest is given to the problems of improving the quality of messaging between traffic networks participants in the areas with low-quality network coverage [1].

Messaging between a vehicle and cloud environment is supplied via dedicated channel, which is organized with the support of telematics hardware equipment [2]. The quality of service in the cloud-oriented environment is determined by reliability of the third party hardware equipment and the size of the coverage area of cellular networks.

As a prospective trend in the development of information network in the areas with unstable signal reception is usually considered as a mobile self-organizing local network of vehicles with the access to cloud environment. In this model the exchange of messages between the vehicle and the cloud can be routed by different paths, then the set of vehicles on the road is presented by wireless LAN with varying topology, with a variable number of points which can communicate with the cloud environment. Currently, wireless messaging methods are supported by various techniques such as: Wi-Fi (802.11bg), mesh (802.11s), 
DSRC, LTE(4G), UMTS(3G), which are implemented in vehicle's on-board hardware equipment [3].

The probability of delivering messages using these technologies may vary significantly at any given moment depending on repeaters location, terrain properties, intensity of data exchange and the amount of data.

Thus, at time $T_{i}$ there arises the problem of choosing the optimal route between two messaging nodes.

Mobile objects connected with each other at the time $T_{i}$ and using the same connection technology build a dynamic network. The network configuration and reliability changes over time.

It is necessary to develop a formal criterion for the well-grounded choice of the best data path at the time moment $T_{i}$. In this paper, the probability of message delivery is considered as such a criterion.

\section{Problem Analysis}

The dynamic network of mobile objects can be represented as a graph $G(U, L)$, where $U_{i}$ is a mobile object, $L_{i j}$ is communication channels between mobile objects. Each data transmission technology determines a subnet, i. e. $G_{m}$ is the subgraph $G_{m} \subset G(U, L)$. Set $F\left(G_{m}\right)$ as a function of the probability of message delivery, defined on the subgraph $G_{m} . T_{i}$ is the time of the message transmission. In this case, the problem will be: at the time moment $T_{i}$ determine $\max \left\{F_{\left(G_{m}\right)}\right\}, m=1 \ldots n$.

The feature of the problem formulation is the restriction on the computation time $F$, as the dynamics of changing parameters $G_{m}$ is high.

Similar problems have been solved in the works of Floyd, Dijkstra, Levit, which represent fundamental research methods to build routes on graphs. In the work presented Dijkstra's algorithms [4] to find the shortest distance from one of the nodes to another, the complexity of the algorithm in the worst case is $O\left(n^{2}\right)$. The Floyd-Warshall algorithm [5] has complexity $O\left(n^{3}\right)$, and Levit's algorithm [5], which is a modified version of the Bellman-Ford algorithm, in the worst case has exponential complexity. However, in practice, the algorithms show good results, with logarithmic complexity
$O(M \log N)$, where $N$ is the set of nodes and $M$ is the set of edges between nodes. These approaches show good results for the routing problems on the networks with low dynamics changes of connected nodes, examples of software implementation for such algorithms are dynamic routing protocols: OSPF and IS-IS. At the same time, their implementation in our task does not provide a solution to linear or constant time. Algorithms to find the shortest path on the graph belong to the class $\mathrm{P}$, and are related to the problems with polynomial complexity. This complexity is due to the necessity to recalculate all routes in the graph, whose structure changes at the time moment $T_{i}$.

The current state of the problem solution: the logical-probabilistic calculus allows connecting Boolean algebra [6] with the operation of the circuit, and network data transmission systems. This allows moving away from the use of classical routing algorithms on graphs and turn to recalculating with the notation of logical variables and probability functions that ensure a quick evaluation form to submit transmission at a constant time in a prearranged structure [7].

\section{Assessment of Message Delivery Reliability by Using a Logical-probabilistic Method}

The logical-probabilistic method is to use a mixed form of the probability function (MFPF) [8], which describes in a compact form the set of conditional probabilities. It takes into account the conditions of the event in the form of logical variables and functions in terms of the degree of event probability.

The logical-probabilistic method (LPM) is originally designed to work with static structures where communication between nodes in the graph is given in terms of the problem, in this structure only communication channels state changes. In order to turn to a dynamic system and to ensure the constant time route calculation the authors propose to introduce dummy nodes, which will manage the appearance and disappearance of vehicles (nodes) at the particular time $T_{i}$. Then a LPM calculation formula could be drawn for the case of the maximum number of nodes (upper limit), and the performance of channels in fictitious nodes until the actual occurrence of the node . 


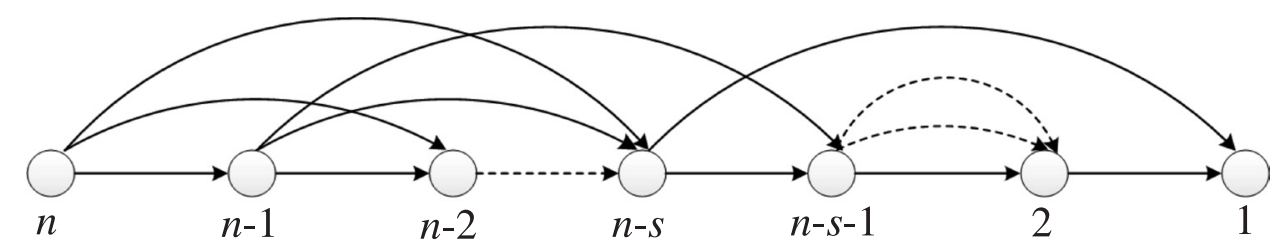

Fig. 1. $s$-connected oriented structure

Consider the application of the logicalprobabilistic method to build estimates of message delivery probability from vehicle $A_{n}$ to $A_{1}$ at the specified time moment $T_{i}$ into the network with incomplete notifying the node of the network status [9].

The graph structure: the vehicle network is represented as a directed acyclic graph. In this graph, each node is represented as a switching center and receiving messages, i. e. each message can be transmitted to the $n$-th destination, if it exists, or a direct path to the destination, or by constructing a chain of hops on workable channels. An example of such a graph is shown in Fig. 1.

The condition of the working system is defined as follows: the system works, if there is at least one workable route from node $n$ to 1 . In its turn, the route is operational, if all its nodes and links between nodes are operational.

Introduce the following notation:

$R_{k}-$ probability of the $k$-th node availability;

$C_{k, s}-$ probability of link availability between $k$-th and $s$-th nodes;

$n$ - number of nodes in the graph (network);

$s$ - number of links between nodes in the graph (network);

$f_{k}-$ logical function of the successful link between nodes;

$k i_{k s}$ - number of the link priority, which is given by the availability coefficient for the $k_{s}$-th link;

$P_{k}-$ total probability of the $k$-th link availability;

$x_{k}$ - logical variable of the $k$-th node availability;

$x_{k, k-1}-$ logical variable of the link availability between $k-1$ and $k$-th nodes;

$Q_{k}$ - probability of the $k$-th node failure;

$L_{k, s}$ - probability of the link failure between $k$-th and $s$-th nodes.
For every node the priority links are defined: $k i_{k 1}, k i_{k 2}, \ldots, k i_{k s},(k>s)$, $k i_{k 1}, k i_{k 2}, \ldots, k i_{k, k-1}(k \leq s)$. Assume for definiteness, the transmission is over the communication channel is working properly in the direction of the lowest numbered node. Then the priority links for all routes from node $k$ to 1 looks like $(k, k-s),(k, k-s+1), \ldots,(k, k-1)$ when $k>s$ and $(k, 1),(k, 2), \ldots,(k, k-1)$ when $(k \leq s)$.

The condition of the network with incomplete input data about elements corresponds to the uncertainty of the status of all nodes and links in route, by which the message is transmitted. In the case of failure of one or more elements of the route, the message will be lost.

The logical-probabilistic method to estimate the probability of the message delivery from node $k$ to node 1 , consists of two stages:

1. Building the logical function of a successful connection between nodes $k$-th and 1 .

2. Building a total probability formula of a successful connection between nodes $k$-th and 1 .

The second stage is realized by the substitution method of logical variables and MFPF building.

Look at the first stage [8].

Find the calculation formula for the probability $R_{k}$ of the message delivery from $k$-th node. Define $f_{k}$ as the logical function of a successful connection between nodes $k$ and 1 . Then $f_{k}$ is realized in the form of the recurrence relation:

$$
\begin{gathered}
f_{k}=x_{k}\left(x _ { k , k - s } f _ { k - s } \vee x _ { k , k - s } ^ { \prime } \left(x_{k, k-s+1} f_{k-s+1} \vee \ldots\right.\right. \\
\left.\left.\ldots \vee x_{k, k-s}^{\prime}\left(x_{k, k-2} f_{k-2} \vee x_{k, k-2}^{\prime} x_{k, k-1} f_{k-1}\right) \ldots\right)\right), \\
s+1 \leq k \leq n, n>s,
\end{gathered}
$$

when $n$ is the number of nodes in the graph, $x_{k}$ is the logical variable of the availability $k$-th node, $x_{k}^{\prime}$ is the logical variable which shows an inoperable state of the $k$-th node. The logical function $f_{k}$ reflects all numerous 
routes to deliver a message in a $s$-connected oriented graph. For example, the expression $x_{k} x_{k, k-s} f_{k-s}$ is interpreted as sending a message through a node using the route $x_{k, k-s}$ and the recurrence relation logical function with the value $f_{k-s}$. If the route $x_{k, k-s}^{\prime}$ fails, the next route $-x_{k, k-s+1}$ will be used and the recursive function calculated for the next value is $f_{k-s+1}$. In the case of $2 \leq k \leq s$, the function will be as follows:

$$
\begin{gathered}
f_{k}=x_{k}\left(x _ { k , 1 } f _ { 1 } \vee x _ { k , 1 } ^ { \prime } \left(x_{k, 2} f_{2} \vee \ldots\right.\right. \\
\left.\left.\ldots \vee x_{k, k-3}^{\prime}\left(x_{k, k-2} f_{k-2} \vee x_{k, k-2}^{\prime} x_{k, k-1} f_{k-1}\right) \ldots\right)\right), \\
2 \leq k \leq s .
\end{gathered}
$$

Look at the second stage.

By the orthogonality of the terms in 1 and 2, substitution variables can be carried out in each term separately. MFPF takes the following form:

$$
\begin{gathered}
P_{k}^{(k-1)}\left(f_{k-1}, \ldots, f_{k-s}\right)=R_{k}\left(1-L_{k, k-s}^{f_{k-s}}+\right. \\
\left.+\sum_{i=k-s+1}^{k-1} \prod_{j=1}^{i-k+s} L_{k, i-j}\left(1-L_{k, i}^{f_{i}}\right)\right), s+1 \leq k \leq n-1 ; \\
P_{k}^{(k-1)}\left(f_{k-1}, \ldots, f_{1}\right)=R_{k}\left(1-L_{k, 1}^{f_{1}}+\right. \\
\left.+\sum_{i=2}^{k-1} \prod_{j=1}^{i-1} L_{k, i-j}\left(1-L_{k, i}^{f_{i}}\right)\right), 2 \leq k \leq s
\end{gathered}
$$

when $P$ is the estimated value for the total probability message delivery from $n$-th node to 1 ; $Q_{k}$ - the probability of the $k$-th node failure; $R_{k}$ - the probability of availability $k$-th node; $L_{k, k-s}$ - the probability of the route failure between $k$-th and $k$-s-th nodes; $C_{k, k-s}-$ the probability of the availability route between $k$-th and $k-s$-th nodes.

Similarly, the substitution is carried out for each term of expression 3. It is convenient to start the substitution in functions with a small number of $k$. After the substitution, we obtain an expression for the total probability of the message delivery from $k$-th node to 1 . According to 3 for any numbers $k \leq s$ we obtain:

$$
\begin{gathered}
P_{k}=R_{k}\left(C_{k, 1} P_{1}+L_{k, 1}\left(P_{2} C_{k, 2}+L_{k, 2}\left(C_{k, 3} P_{3}+\right.\right.\right. \\
\left.\left.+\ldots+L_{k, k-2} C_{k, k-1} P_{k-1}\right)\right) .
\end{gathered}
$$

Similarly for $k>s$ :

$$
\begin{gathered}
P_{k}=R_{k}\left(C_{k, k-s} P_{k-s}+L_{k, k-s} \times\right. \\
\left.\times\left(C_{k, k-s+1} P_{k-s+1}+\ldots+L_{k, k-2} C_{k, k-1} P_{k-1}\right)\right) .
\end{gathered}
$$

Thus, knowing the vector of probabilities of availability $R_{i}$ and $C_{i, j}$, we can calculate the probability of the message delivery from $k$-th node to 1 for each channel technology. For $m$ available channels by different technologies it is easy to get $m$ values of the probability message delivery, and the computational complexity of the calculation will be no higher than the linear one.

\section{Example of Calculating the Probability of Message Delivery}

Consider the example of calculating the probability of message delivery between $k$-th nodes with two different channel technologies $a_{i} \quad b_{i} \quad i=1 \ldots k$ on each node. Transmitters of each technology are combined in isolated networks $A$ and $B$. In this case, the function for calculating the probability is used as a decision in the route selection process of transmitting messages between nodes through the network $A$ or $B$. Let each network be defined by the fully connected topology, which presented in Fig. 2.

The calculation example for the first four nodes is shown below in (6), (7). The calculation of the elements to the $k$-th element is carried out according to the MFPF formula (4) recurrently substituting the corresponding $k-1$ states.

This formula evaluation is based on formula (1) and (2). Later the logical function of successful communication between nodes for each of the two channels becomes:

$$
\begin{gathered}
f_{4}\left(P_{4}=1\right)=x_{4}\left(x_{34} x_{3} \vee x_{24} f_{2} \vee x_{41} x_{1}\right), \\
f_{4}=x_{1}\left(x_{34} f_{3} \vee x_{24} f_{2} \vee x_{14} f_{1}\right),
\end{gathered}
$$

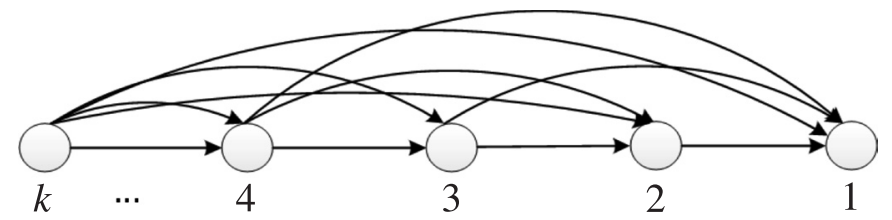

Fig. 2. Network topology example for different channel technologies 


$$
\begin{gathered}
f_{3}=x_{3}\left(x_{23} f_{2} \vee x_{13} f_{1}\right), \\
f_{2}=x_{2}\left(x_{12} f_{1}\right), \\
f_{1}=x_{1} .
\end{gathered}
$$

For example, for the first four nodes MFPF takes the following form:

$$
\begin{gathered}
P_{2}=R_{2} R_{21} R_{1}, \\
P_{3}=R_{3} R_{1}\left(R_{31}+L_{31} R_{32} R_{2} R_{21}\right), \\
P_{4}=R_{4} R_{1}\left(R_{41}+L_{41} R_{42} R_{2} R_{21}+\right. \\
\left.+L_{42} R_{43} R_{3}\left(R_{31}+L_{31} R_{32} R_{2} R_{21}\right)\right) .
\end{gathered}
$$

The obtained values $P_{4}$ are the probability of the message delivery through channels $A B$. For the $k$-th node the following form is recurrently calculated from formula (4).

To calculate the numerical value of the message delivery probability through the channel $a$, it is required to set the vector probabilities of availability nodes and links of communication network $A$ - vector $R_{A}=\left\{r_{1}^{A}\right.$, $\left.r_{2}^{A}, r_{3}^{A}, r_{4}^{A}, \ldots, r_{k}^{A}\right\}$ and vector $S_{A}=\left\{r_{i j}^{A}, \ldots, r_{43}^{A}\right.$, $\left.r_{42}^{A}, r_{41}^{A}, r_{32}^{A}, r_{31}^{A}, r_{21}^{A}\right\}, 2 \leq i \leq k, 1 \leq j \leq k-1$. For the channel technology $b$ state of nodes and links $B$ are determined by the values of vectors: $R_{B}=\left\{r_{1}^{B}, r_{2}^{B}, r_{3}^{B}, \ldots, r_{k}^{B}\right\} \quad$ and $S_{B}=\left\{p_{i j}^{B}, \ldots, p_{43}^{B}, p_{42}^{B}, p_{41}^{B}, p_{32}^{B}, p_{31}^{B}, p_{21}^{B}\right\}$. The probability of availability nodes and links set in the range: $0 \leq r_{i} \leq 1$ and $0 \leq r_{i j} \leq 1$ channels for both networks technologies.

\section{REFERENCES / СПИСОК ЛИТЕРАТУРЫ}

1. Zaborovskiy V., Lukashin A., Popov S., Vostrov A. Adage Mobile Services for its Infrastructure. ITS Telecommunications, 13th International Conference on, 2013, Pp. 127-132.

2. Zaborovski V.S., Chuvatov M., Gusikhin O.Y. Heterogeneous Multiprotocol Vehicle Controls Systems in Cloud Computing Environment, ICINCO, 2013, Vol. 1, Pp. 555-561.

3. Glazunov V., Kurochkin L., Kurochkin M., Popov S., Timofeev D. Road traffic efficiency and safety improvements trends, ICINCO, 2013, Vol. 2, Pp. 439-446.

4. Dijkstra E.W. A Note on Two Problems in Connexion with Graphs, Numerische Mathematik, 1959, Vol. 1, Pp. 269-271.

5. Cormen T.H., Leiserson C.E., Rivest R.L., Stein C. Introduction to Algorithms, 2nd ed. The MIT Press, 2001. 1981. (rus)
After all the substitution to $R_{A}, S_{A}$ and $R_{B}, S_{B}$, obtain the values $P_{k}^{A}$ and $P_{k}^{B}$.

The higher of the two values $P_{k}$ for networks $A$ and $B$ determine the channel $a$ or $b$ node $r_{i}$, on which the message will be transmitted.

\section{Conclusion}

The search for the optimal route of transferring data during a limited time interval is a key problem to implementing a cloud-oriented mobile mesh-network [2, 3]. The logical-probabilistic method of building the evaluation of messaging routes allows shortening the time needed to calculate the probability of delivering a message over the given channel and define the best route of delivering the message at any moment [10]. The strength of such an approach is in the ability to find an analytic solution in a common case with the incomplete input data about the network elements condition. This paper includes an example with the calculation of probability of the message delivery for the network of the fully connected acyclic graph. The presented example demonstrates the solution to the problem of searching for a new route in the case of data transfer session interruption when the transmission time is longer than networking the lifetime, which is important when transmitting a large amount of data by high-level protocols.

6. Bryant R. Graph-Based Algorithms for Boolean Function Manipulation, IEEE Trans. Comput., 1986, Vol. 35(8), Pp. 677-691.

7. Balan A.O. An Enhanced Approach To Network Reliability Using Boolean Algebra, An Honors Thesis presented to the Departments of Computer Science and Mathematics of Lafayette College, 2003, Pp. 1-43.

8. Ryabinin I., Cherkesov G. The logic-probabilistic research methods of structure-complex systems reliability. Moscow: Radio i svyaz Publ.,

9. Ito M. Probabilistic Communication Net as a Nonoriented Graph. Reliability, IEEE Transactions on. 1975, Vol. R-24, No. 3, Pp. 196-198.

10. Glazunov V., Kurochkin L., Kurochkin M., Popov S. Instrumental environment of multiprotocol cloud-oriented vehicular mesh network, ICINCO, 2013, Vol. 1, Pp. 568-574. 
GLAZUNOV, Vadim V. St. Petersburg Polytechnic University.

195251, Politekhnicheskaya Str. 29, St. Petersburg, Russia.

E-mail: neweagle@gmail.com

ГЛАЗУНОВ Вадим Валерьевич - аспирант кафедры телематики Института прикладной математики и механики Санкт-Петербургского государственного политехнического университета.

195251, Россия, Санкт-Петербург, ул. Политехническая, д. 29.

E-mail: neweagle@gmail.com

KUROCHKIN, Mikhail A. St. Petersburg Polytechnic University.

195251, Politekhnicheskaya Str. 29, St. Petersburg, Russia.

E-mail: kurochkin.m@gmail.com

КУРОЧКИН Михаил Александрович - профессор кафедры телематики Института прикладной математики и механики Санкт-Петербургского государственного политехнического университета, кандидат технических наук.

195251, Россия, Санкт-Петербург, ул. Политехническая, д. 29.

E-mail: kurochkin.m@gmail.com

POPOV, Sergey G. St. Petersburg Polytechnic University.

195251, Politekhnicheskaya Str. 29, St. Petersburg, Russia.

E-mail: popovserge@spbstu.ru

ПОПОВ Сергей Геннадьевич - доцент кафедры телематики Института прикладной математики и механики Санкт-Петербургского государственного политехнического университета, кандидат технических наук.

195251, Россия, Санкт-Петербург, ул. Политехническая, д. 29.

E-mail: popovserge@spbstu.ru 